\title{
The Future of Work in a Jobless Society: Globalization, Smart Digitalization, and Cognitive Automation
}

\author{
Irina Dijmărescu ${ }^{1,}$ Luminița Ionescu ${ }^{2, *}$ \\ ${ }^{1}$ Alexandrescu Children's Emergency Hospital, Department of Paediatrics, 011743 Bucharest, \\ Romania \\ ${ }^{2}$ Spiru Haret University, Department of Economics, Fabricii 46G, 060821, Bucharest, Romania
}

\begin{abstract}
.
Research background: The future of work is undoubtedly one of the toughest challenges faced by many researchers and managers all over the word. The new era in digital globalization and smart digitalization, the trends in robotization and artificial intelligence have changed the labour market. Due to accelerated technology, many companies are ready to adopt digital solutions, stationary robots and drones with significant consequences over the declining jobs. The new human-machine frontier will determine a different outlook work in a jobless society, where many roles become automated, while human's role in these processes is minimized.

Purpose of the article: In our opinion, globalization and impact of artificial intelligence on the future of work will be significant. In this paper we try to analyse and clarify the issues in question in terms of smart digitalization, cognitive automation, human-machine frontier and changing employment types. The data used for this research was obtained from previous study conducted by World Bank and OECD.

Methods: In order to fulfil our goal, we apply the methods of comparison, analysis, deduction and our estimates for identifying the trends that are shaping the future of jobs and the evolution of jobs caused by technological change.

Findings \& Value added: In the near future, innovation will continue to accelerate and many artisan jobs are being lost to computerization and office automation. Finally, we formulate our own conclusion and view about digitalization and opportunities to create new jobs, increase productivity, and cost reduction, through innovation and accelerating change.
\end{abstract}

Keywords: artificial intelligence; business automation; smart economy; human labour

JEL Classification: $H 12 ; J 01 ; M 15 ; M 48$

*Corresponding author: luminitaionescu2003@yahoo.com 


\section{Introduction}

The relationship between big data and cloud computing is strong and complex, but cloud computing provides major solutions for big data $[3,5]$ while accelerating the benefits of digital data management. Big data can be used, reused, moved and modified with low cost at fast speed, bringing about good results for top management. In the last decades, the future of work in the digital activities has become uncertain due to disruptive technologies that will allegedly create jobless growth and worldwide unemployment [1]. The future of work is changing as the result of globalization, smart digitalization and cognitive automation. Thus, there are many alarming predictions about the changing nature of work and skills in the digital age [2] and strong challenges will be faced by many researchers and managers all over the word. The new digital accelerated technology will reshape jobs all over the world with significant impact over businesses and recruitment [1]. The new human-machine frontier will determine a different view over the future of work in the jobless society, because our society is increasingly confronted with automation, not only in robotics market and behind fences in factories [3, 24], but also on daily activities. The current trend of labour market is changing as a result of three simultaneous important shifts [1]:

- A demographic shift, including an aging population, especially in Europe;

- The economic shift of digital globalization, that creates digital platforms and changes the economics of doing business across borders;

- A technological shift, driven by the Internet, including artificial intelligence, big data and cloud computing.

Digitalization changes the economics of globalization in several ways, with significant consequences over the future of work $[4,5]$. In the European Union (EU), the technological revolution is causing significant changes in the labour market and some jobs are at risk of being lost to machines [5].

\section{Methods and Data}

We developed our research based on data collected from the Eurostat, World Bank and OECD databases. Thus, according to the Eurostat, technology is a key driver of new forms of work and it is a big demand in ICT specialists in the European countries [5,6]. Despite the increasing number of advanced digital skills graduates, statistics report that, in 2018, $53 \%$ of companies had difficulties in filling vacancies with ICT specialists [5].

We performed some research and made some estimates based on the human-machine frontier and changing employment types and we present the evolution of jobs caused by technological change in the digital world. 


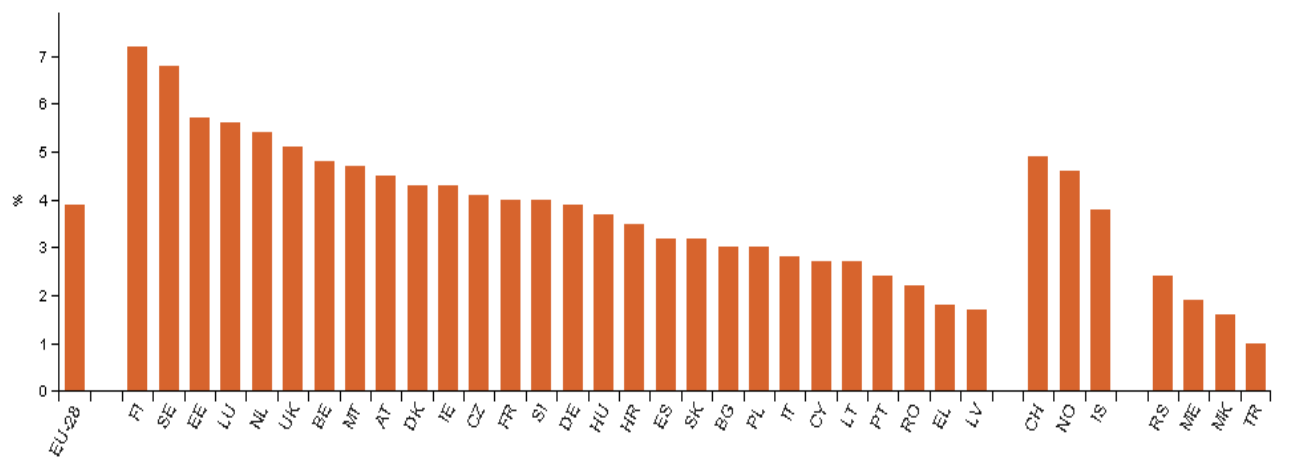

Fig. 1. Proportion of ICT specialists in total employment in 2018

Source: https://ec.europa.eu/eurostat/statistics-explained/index.php/ICT_specialists_in_employment

In a recent study for the OECD, automation is perceived as a threat that will ultimately foster technological unemployment. Thus, smart digitalization and continuously progressing robotic process automation will transform jobs and but also have begun to have an impact on how work is performed and structured in the next few years $[6,7,25]$.

The advanced technologies are likely to enhance productivity and efficiency, but also will create new jobs in the digital world, boosting consumer demand and generating new revenue streams. According to the World Bank, the share of automatable jobs varies between $6 \%$ in Korea and $12 \%$ in Austria (see figure 2) and the jobs with high automatability percentage will be found in Spain, Germany or Austria, while the lowest will be found in Korea and Estonia (6\%) or Belgium (7\%).

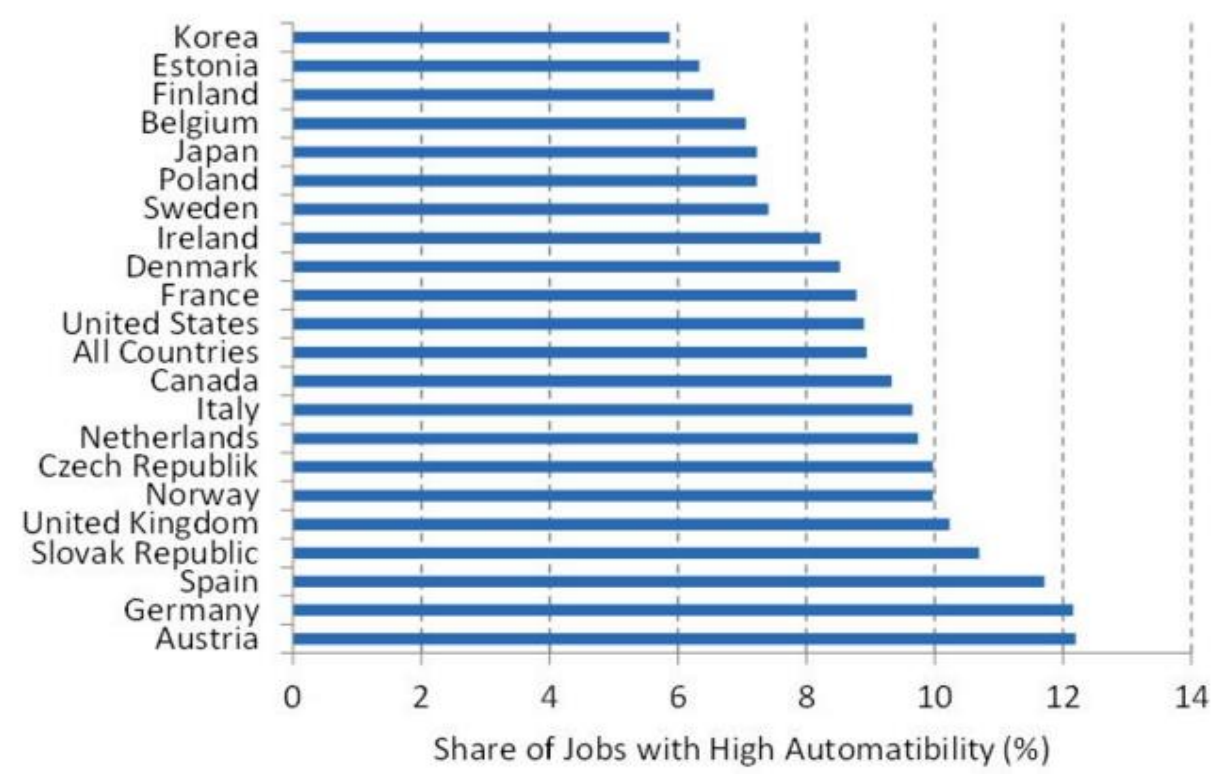

Fig. 2. Share of jobs with high automatability

Source: https://blogs.worldbank.org/jobs/digitization-unlikely-destroy-jobs-may-increase-inequalities

The utilisation of digital solutions in terms of data and computer availability allow for automating a substantial share of jobs in the near future. The latest OECD Regional Outlook (2019) shows that the prevalence of jobs at risk of automation is much higher than 
average for example in eastern Europe (Slovakia, Slovenia, Poland) and southern Europe (Greece, Spain), while Nordic countries and the UK seem to face a lower risk (see figure 3).

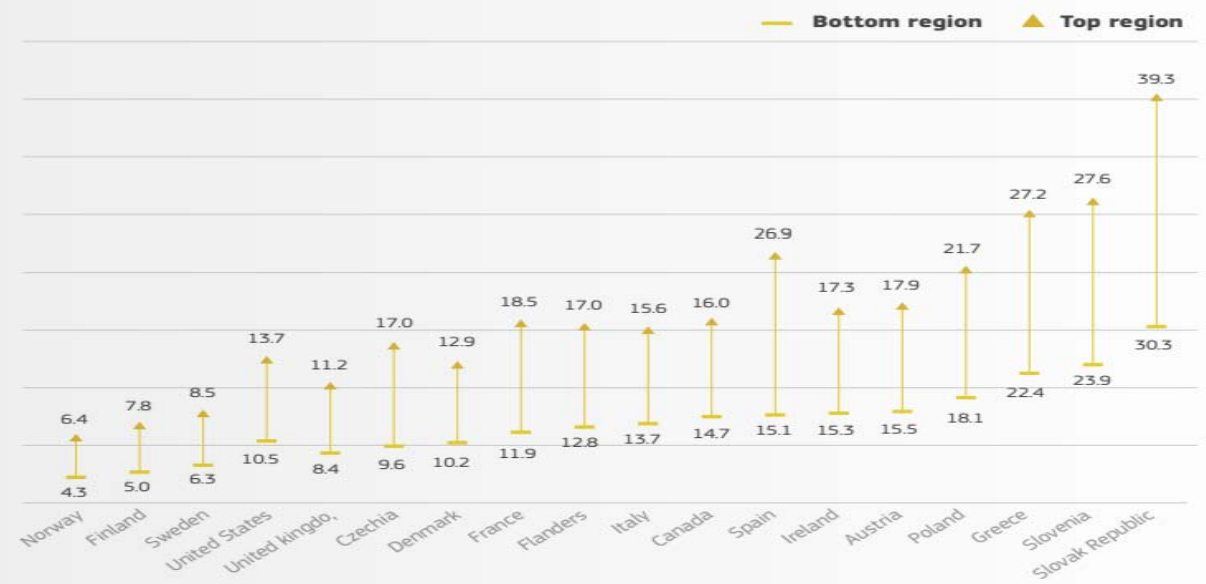

Fig. 3. Percentage of jobs at high risk of automation by country (2016)

Source: https://ec.europa.eu/jrc/en/publication/eur-scientific-and-technical-research-reports/changingnature-work-and-skills-digital-age

\section{Results and Discussion}

Current technologies will affect jobs all over the world, but some industries could be more affected than others. For example, banking, insurance, accounting, and auditing services face a high risk of becoming automated in the near future and accounting procedures will be performed by robotics engineers and blockchain specialists. In the same time, medical practitioners, dental practitioners, higher education teachers and senior professionals in education present a low risk of becoming automated and replaced by robots or artificial intelligence. Office for National Statistics (ONS) from UK analysed the jobs of millions of people in 2017 and found that some of these were at high risk of being replaced.

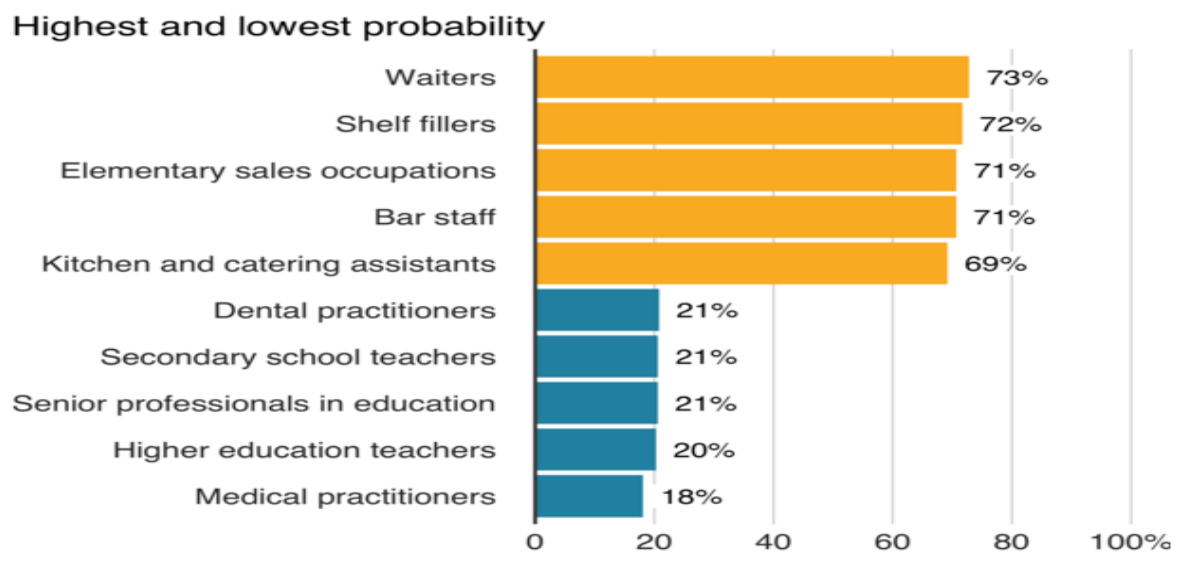

Fig. 4. Jobs at risk from automation in England (2017) Source: https://www.bbc.com/news/business-47691078

According to World Economic Forum 2019, smart digitalization and cognitive automation will create new jobs $[16,19]$, and some range of roles that are set to experience increasing demand in the period up to 2022 , such as data analysts and scientists, software 
and applications developers, and ecommerce and social media specialists that are significantly based on and enhanced by the use of the digital technology.

The economic outlook for the future of work will be different shortly and employers will require different skills from workers compared to previous decades [11, 21, 22]. In our opinion, the workers are facing shifting skills demand from job opportunities in expanding businesses. We present in the table below the new jobs with increasing demand in 2019.

Table 1. New jobs and new skills required on the job market in $2019(\%)$

\begin{tabular}{|l|r|}
\hline Data analysts & 25 \\
\hline General and operational managers & 21 \\
\hline Computer specialists & 20 \\
\hline Digital marketing specialists & 18 \\
\hline Big data specialists & 13 \\
\hline Other & 3 \\
\hline
\end{tabular}

Sources: Market Research; our survey among 2,500 individuals conducted July-August 2020.

Artificial intelligence offers unique capacities for automating cognitive work and certain activities are more likely to be automated [8], but some activities must be performed only by humans. In the digital globalization era, accelerated technology will displace some workers while at the same time create new opportunities for others. We present in the table below the new work tasks performed by employees in 2019 .

Table 2. Work tasks performed by employees in 2019 (\%)

\begin{tabular}{|l|r|}
\hline Decision-making & 51 \\
\hline Coordinating, developing, advising & 21 \\
\hline Communicating and interacting & 17 \\
\hline Administering & 9 \\
\hline Others & 2 \\
\hline
\end{tabular}

Sources: Market Research; our survey among 2,500 individuals conducted July-August 2020.

Traditionally, industrial robots perform assembly steps in isolation from people, continuously repeating a carefully predefined sequence of actions $[9,18]$, but in the near future, specialists expect a shift in the human-machine frontier. The market research provides a nuanced view of how human-machine collaboration might develop up to 2022 due to automation, while human's role in these processes is minimized. We present in the table below the new human-machine collaboration estimated up to 2022 .

Table 3. The new human-machine collaboration estimated up to 2022 (\%)

\begin{tabular}{|l|r|}
\hline Information and data processing & 45 \\
\hline Performing complex and technical activities & 30 \\
\hline Performing physical and manual work & 20 \\
\hline Others & 5 \\
\hline
\end{tabular}

Sources: Market Research; our survey among 2,500 individuals conducted July-August 2020..

The future of jobs cannot be predicted for sure, but the implementation of the digital technology continues to accelerate and the future of work is predominantly online, using digital platforms in some specific industries, such as: insurance, finance, accounting, banking, etc. $[10,11,23]$. The vision for the future of jobs is related to digital platforms, where technology is developed with automation, robotisation and artificial intelligence, that will determine human work unnecessary in some industries [12, 13, 17]. The interaction between human workers and machines has evolved over time $[14,20]$ from the level when workers were trained to use the machines and to the present day when robots and artificial 
intelligence are developing business and performing more advanced functions. However, artificial intelligence is evolving by itself and some modern equipment has developed so quickly that it is difficult for human workers to use them on daily basis $[14,15]$. Machine learning is used often in digital platforms that capture vast amounts of data and many activities that human workers carry out today have the potential to be automated in the near future $[18,19]$.

\section{Conclusions and Implications}

The projections for the future of jobs in the digital world are related to the structural change in the labour global market [16] and the evolution of human-machine interaction in the next decade. In our opinion, the rise of workplace automation in so many forms has the potential to vastly improve productivity, while increasing efficiency, safety, and convenience. In the same time, the fourth industrial revolution is minimizing the human role, due to innovation and accelerating change. The projected human-machine interaction indicates that the ratio human-machine working hours will change to more hours performing by machines with modern technology that will substitute humans.

Globalization and digitalization will create new jobs and additional opportunities will appear on the labour market. The impact of digitalisation on the workforce is changing mentality and culture all over the world, and many jobs are likely to disappear in the near future, but some others types of jobs are being created. Innovation continues to accelerate and new workers benefit from the digital transformation for new jobs, like computer specialist, data analyst, big data specialist, robotic engineer, blockchain specialist, Internet of Things architect, etc. Internet platforms have emerged to connect business and people in a global economy. Thus, the decision to invest in the workforce reskilling is crucial. Qualified workers with mixed skills ready for augmentation may find new opportunities on the global market and job quality will increase considerably [16].

\section{References}

1. Peters, M.A. (2020). Beyond Technological Unemployment: The Future of Work. Educational Philosophy and Theory, 52(5), 485-491.

2. Boyd, J.A., Huettinger, M. (2019). Smithian Insights on Automation and the Future of Work. Futures Journal, 111, 104-115.

3. Flemisch, F., Abbink, D. A., Itoh, M., Pacaux-Lemoine, M.P., Weßel, G. (2019). Joining the Blunt and the Pointy End of the Spear: Towards a Common Framework of Joint Action, Human-machine Cooperation, Cooperative Guidance and Control, Shared, Traded and Supervisory Control. Cognition, Technology \& Work, 21(4), 555568.

4. McKinsey Global Institute (2016). Digital Globalization: The New Era of Global Flows, available at https://www.mckinsey.com/ /media/McKinsey/Business $\% 20$ Functions/McKinsey\%20Digital/Our\%20Insights/Digital\%20globalization\%20The\%2 0new\%20era\%20of\%20global\%20flows/MGI-Digital-globalization.

5. European Commission (2019). The Changing Nature of Work and Skills in the Digital Age, Publications Office of the European Union, available at https://ec.europa.eu/jrc/en/publication/eur-scientific-and-technical-research-reports/ changing-nature-work-and-skills-digital-age.

6. Hofmann, P., Samp, C., Urbach, N. (2020). Robotic Process Automation. Electronic Markets, 30(1), 99-106. 
7. Cherry, M. A. (2020). Back to the Future: A Continuity of Dialogue on Work and Technology at the ILO. International Labour Review, 159(1), 1-23.

8. Jarrahi, M. H. (2019). In the Age of the Smart Artificial Intelligence: AI's Dual Capacities for Automating and Informating Work. Business Information Review, 36(4), 178-187.

9. Wojtak, W., Ferreira, F., Vicente, P., Louro, L., Bicho, E., Erlhagen, W. (2020). A Neural Integrator Model for Planning and Value-Based Decision Making of a Robotics Assistant. Neural Computing and Applications.

10. Ionescu, L. (2019). Big data, Blockchain, and Artificial Intelligence in Cloud-Based Accounting Information Systems. Analysis and Metaphysics, 18, 44-49.

11. Ionescu, L. (2019). Would Taxing the Robots Curtail Technological Advancement or Mitigate the Risks of Automation? Contemporary Readings in Law and Social Justice, 11(1), 33-38.

12. Ram, J., Zhang, C., Koronios, A. (2016). The Implication of Big Data Analytics on Business Intelligence: A Qualitative Study in China. Forth International Conference on Recent Trends in Computers Science \& Engineering, Elsevier, Procedia Computer Science, 87, 221-226.

13. Naastepad, W. M., Budd, C. H. (2019). Preventing Technological Unemployment by Widening our Understanding of Capital and Progress: Making Robots Work for Us. Ethics and Social Welfare, 13(2), 115-132.

14. Di Nardo, M., Florentino, D., Murino, T. (2020). The Evolution on Man-machine Interaction: The Role of Human in Industry 4.0 Paradigm. Production \& Manufacturing Research, 8(1), 20-34.

15. Jung, J. (2019). The Fourth Industrial Revolution, Knowledge Production and Higher Education in South Korea. Journal of Higher Education Policy and Management, 42(2), 134-156.

16. WEF (2019). The Future of Jobs Report. Retrieved from: https://www.weforum.org/reports/the-future-of-jobs-report-2018.

17. Coatney, K. (2019). Cyber-Physical Smart Manufacturing Systems: Sustainable Industrial Networks, Cognitive Automation, and Big Data-driven Innovation. Economics, Management, and Financial Markets, 14(4), 23-29.

18. Drennan-Stevenson, K. (2019). Real-World Implementation of Cyber-Physical Production Systems in Smart Manufacturing: Cognitive Automation, Industrial Processes Assisted by Data Analytics, and Sustainable Value Creation Networks. Journal of Self-Governance and Management Economics, 7(3), 14-20.

19. Tuffnell, C., Kral, P., Siekelova, A., and Horak, J. (2019). Cyber-Physical Smart Manufacturing Systems: Sustainable Industrial Networks, Cognitive Automation, and Data-Centric Business Models. Economics, Management, and Financial Markets, 14(2), 58-63.

20. Nica, E. (2019). Cyber-Physical Production Networks and Advanced Digitalization in Industry 4.0 Manufacturing Systems: Sustainable Supply Chain Management, Organizational Resilience, and Data-driven Innovation. Journal of Self-Governance and Management Economics, 7(3), 27-33.

21. Kral, P., Janoskova, K., Podhorska, I., Pera, A., and Neguriță, O. (2019). The Automatability of Male and Female Jobs: Technological Unemployment, Skill Shift, and Precarious Work. Journal of Research in Gender Studies, 9(1), 146-152. 
22. Kovacova, M., Kliestikova, J., Grupac, M., Grecu, I., and Grecu, G. (2019). Automating Gender Roles at Work: How Digital Disruption and Artificial Intelligence Alter Industry Structures and Sex-based Divisions of Labor. Journal of Research in Gender Studies, 9(1), 153-159.

23. Groener, M. (2019). Automated Robotic and Network Connectivity Systems for SelfDriving Vehicle Technology. Contemporary Readings in Law and Social Justice, 11(2), 36-42.

24. Tooby, C. (2019). Governance Mechanisms of Analytical Algorithms: The Inherent Regulatory Capacity of Data-driven Automated Decision-Making. Contemporary Readings in Law and Social Justice, 11(1), 39-44.

25. Gutschow, E. (2019). Big Data-driven Smart Cities: Computationally Networked Urbanism, Real-Time Decision-Making, and the Cognitive Internet of Things. Geopolitics, History, and International Relations, 11(2), 48-54. 